\title{
Optic Neuritis
}

National Cancer Institute

\section{Source}

National Cancer Institute. Optic Neuritis. NCI Thesaurus. Code C84950.

A disorder characterized by inflammation of the optic nerve. Causes include autoimmune disorders, infections, toxins, drugs, and multiple sclerosis. It may manifest with acute loss of vision and pain. 